\title{
Recent Enhancements to the Biosystems Engineering Design Trilogy at the University of Manitoba
}

\author{
Danny D. Mann, Kris J. Dick and Sandra A. Ingram \\ Department of Biosystems Engineering, University of Manitoba, Winnipeg, MB R3T 5V6 \\ Corresponding Author E-mail Address: Danny_Mann@umanitoba.ca
}

\begin{abstract}
In previous years, several improvements to the teaching of engineering design were made by staff in the Department of Biosystems Engineering at The University of Manitoba. The first innovation occurred when a trilogy of courses spanning the final three years of the program was introduced as a replacement for a single capstone course in the final year of the program. In its original conception, engineering students were to get three opportunities to be involved in design problems originating from industry, with greater expectations with each subsequent experience. A second innovation occurred when technical communication was formally integrated within the trilogy of design courses. This innovation has helped engineering students realize the value of professional communication skills in collaborating with each other and in preparing reports and presentations for an industry client. A third innovation occurred three years ago when the decision was made to allow students to participate in the prototyping of their designs. The so-called "Design Trilogy" now consists of a single course (Design Trilogy I) taken during the second year of the engineering program (which builds upon the first-year design experience with the requirement of a conceptual solution in response to a design problem provided by industry) and two courses taken during the final year of the program. Students are required to have a design completed on paper by the completion of Design Trilogy II and fabrication of the prototype occurs during Design Trilogy III. The student experience in the Design Trilogy, with particular emphasis on curriculum innovations in Design Trilogy III, will be discussed.
\end{abstract}

Keywords: capstone design, prototyping, engineering education, hands-on training, communication

\section{INTRODUCTION}

Society expects that engineers should be able to design practical solutions to problems. Employers hire engineers with the expectation that they can design workable, affordable solutions to problems. Accreditation bodies require graduating engineers to be able to design. It is the role of the university in relation to these demands, to ensure that graduating engineers are capable of meeting these expectations.

A lack of appropriate design training in the engineering curriculum has been identified by several authors $[4,10,11]$. Design training may be inadequate if engineering students are not able to apply fundamental engineering principles to solve practical problems. This ability has been observed to be a weakness of engineering students [3]. Logically, this weakness may be due to an inadequate knowledge of fundamental engineering principles or an inadequate knowledge of the design process. Of these two potential causes, it is likely that engineering students have an inadequate knowledge of the design process because there is already much emphasis on the delivery of fundamental engineering principles.

Various models of the design process have been presented in the literature $[1,2,5,6,9]$. Although the models are not all identical, the design process is typically considered to cover all of the steps from the initial stage of project planning through to manufacturing of the product (some models even include marketing as the final step in the design process). In 1999, a review of the Biosystems Engineering curriculum at The University of Manitoba revealed that students graduating from the program did not experience the entire design process. Three design courses (which have come to be known as our "Design Trilogy") were created to provide an opportunity to provide students with an adequate knowledge of the design process. 


\section{ORIGINAL CONCEPT OF THE DESIGN TRILOGY}

The original objectives for the Design Trilogy were quite ambitious. The overall objective was to teach undergraduate Biosystems Engineering students the entire design process from formulation of the problem to fabrication of a prototype. Within this overall objective, the following specific objectives were set: i) to strengthen team building skills, ii) to strengthen communication skills (all aspects), iii) to instill a sense of professionalism, iv) to develop project and business management skills, and v) to instill safety and human factors engineering principles. As originally taught, the Design Trilogy consisted of three, 4-credit hour courses (one offered at the second, third, and fourth-year levels). During second year, students were expected to develop a conceptual solution in response to a problem submitted by industry. During third year, students were expected to provide a detailed design complete with engineering drawings and analysis. During fourth year, students were expected to provide a final design complete with an economic analysis and an in-depth engineering analysis. It is important to note that the original offering of the Design Trilogy did not expose students to the prototyping stage of the engineering design process.

The three courses were scheduled in the same time slot to allow coordination between the three courses. Joint brainstorming sessions included students from all three years. Oral progress reports were scheduled during joint sessions to enable the second-year students to observe the strategies and techniques used by their more experienced senior classmates. Finally, students in the final Design Trilogy course were required to sub-contract a portion of their design project to a junior engineering student in one of the other Design Trilogy courses.

Although coordination between the three courses was envisioned as a means of strengthening team skills, communication skills, and professionalism, we were never completely satisfied with the results. The process of sub-contracting design tasks was problematic because the fourth-year students had a hard time knowing what tasks to sub-contract. In other cases, the sub-contractors performed sub-par work because the deadlines seemed to interfere with their own assignments (and they chose to devote more time to their own design projects rather than fulfilling their contractual obligations).

Despite challenges experienced with some of the activities intended to bring together students from the three separate courses of the Design Trilogy, the overall concept of providing Biosystems Engineering students with three opportunities to be exposed to an industry design problem was considered a success. Engineering design is complex. From a pedagogical perspective, there is value in providing multiple opportunities for students to practice (a concept known as "mastery learning").
Virtually all models depict the engineering design process as being iterative in nature. Iterations are driven by new knowledge that becomes available as the process evolves. It is the new knowledge, and the subsequent iteration, that leads to change in the ultimate design. The process of designing the "Design Trilogy" is no different. As instructors, we are committed to using feedback and observations to make modifications to the Design Trilogy. In the upcoming sections, three substantial changes will be discussed. Two of these changes have been successful and can be classified as innovations in the teaching of capstone design.

\section{DESIGN TRILOGY INNOVATIONS}

\subsection{Experiences with Inter-year Design Teams}

In industry, it is common for a design team to be comprised of both senior leaders and junior members. Different roles are played depending on one's level of experience. Inter-year design teams (what is referred to as "vertical integration" in the education literature) were formed in the 2006-07 academic year. Each design team consisted of one or two students from each of the three Design Trilogy courses. The students registered in the fourth-year course were expected to assume the leadership roles for the project based on having more experience.

Despite great optimism at the beginning of the 2006-07 academic year, the experiment with inter-year design teams was not successful. A paper describing the student reaction and instructor observation was presented at the CDEN conference in 2007 [7]. Briefly, there were four issues that prevented the experience from being successful. First, the design teams had great difficulty scheduling team meetings because they were all on different academic schedules. Team leadership was an issue because fourth-year students were mandated (by the course instructors) to take leadership positions even though those with natural leadership skills may in fact, have been second or third-year students. Assignment of team responsibilities was the third issue. In some cases, the fourth-year students failed to involve the junior students and, therefore, the desired mentoring did not occur. Finally, the forced integration of students from different years in the program prevented the informal design time that would normally occur during the breaks between classes (e.g. as students walked from class to class). Because the team members were on different academic schedules, they tended to be together only during the scheduled class time. Until the end of the semester when students were informally surveyed, the importance of that informal design time to the success of the design team was not known. The experiment with inter-year design teams lasted only one academic year because of these four challenges. 


\subsection{Integration of Technical Communication with the Capstone Experience}

Although one of the original objectives of the Design Trilogy had been to strengthen communication skills among engineering students, the first iteration of the Design Trilogy in 1999 contained little innovation related to the teaching of technical communication. The innovation occurred when a decision was made to formally integrate the teaching of technical communication with the teaching of the design process (i.e., the capstone experience). Prior to this innovation, the Biosystems Engineering program was like many other engineering programs in the sense that students completed a stand-alone technical communications course. Essentially, students learned how to write a technical report in the technical communications course and they had opportunity to complete a design project in the capstone course (in this case, the Design Trilogy). The two experiences were separate and students did not realize the benefit of learning how to become an effective communicator. The challenge was to create an environment where students would receive instruction related to both technical communications and the design process within the context of completing a design project for an industry client. If a conducive learning environment could be created, it was hypothesized that students would see the link between their coursework and work-life settings and thus have a keener appreciation of the value of the communication component. The experience of integrating technical communication with the capstone experience has largely been a success. Since 2003, Biosystems Engineering students no longer take the Faculty of Engineering's stand-alone "technical communications" course. Content that is equivalent to a three credit course in technical communications has been added to the three courses of the Design Trilogy (i.e., $25 \%$ of the first course, $50 \%$ of the second course, and $25 \%$ of the third course and is taught by an instructor with expertise in technical communication. Further details on some of the early innovations made have been documented elsewhere [8]. Since that time and more specifically in the re-working of the fourth year course into its current form, in the last three years, communication efforts have expanded to include resume and cover letter workshops and assignments, and the adoption of 'speed interviews' in which students travel in pairs in the classroom setting to be interviewed by six or seven 'mock' employers. We call upon engineers from industry, human resource specialists and former graduates to ask questions of the students and then assess them on their technical and professional skills sets in preparation for their entry into the engineering workplace.

Also, as a transition between third and fourth year courses at the end of the second year of the trilogy, we have introduced a presentation format that showcases students' oral presentation skills in a different format than the conventional and often overused power-point method. We ask students to reflect on their experiences in Design II and their contributions to the conceptual phase of their project. The approach is modeled after the jury process typical in studio courses in architecture. Members of each team prepare a single "storyboard" that summarizes their contribution to the project. Storyboards are placed on easels at the front of the class. Seating is arranged in a semi-circular fashion to create a more intimate environment. Industry partners, department technicians, course instructors, a design colleague from architecture and the students provide comments. The essence of this process is to provide "constructive criticism" for the design team prior to building a prototype. From a pedagogical point of view, this process provides course instructors with a clearer sense of each student's contribution to the project. The feedback from this process informs each team's progress report submitted at the end of term.

This approach also reinforces the importance of keeping a journal. Students are reminded that a good journal record is fundamental to evaluating their contribution to the design process. Each student turns in a journal on a weekly basis for both Design II and III. It is intended to be a reflective document in which students record all project-related tasks, including the research process, design ideas (along with relevant sketches) and meetings held.

Another component of Design II is reinforcing the importance of drawing skills. Written, oral and drawing skills all speak to the importance of engineering communication. During Design II students refresh their knowledge of fundamental drawing including orthographic projection, sketching and formal drawing. All students are required to prepare hand-drawn plans for the proposal submitted at the end of Design II. While this has met with mixed reviews the rationale is simply that it is not possible to evaluate students' competency with computer drawing programs such as Autocad. The pedagogical rationale is based on the reality that each student does not have a laptop in class to allow the instructor to evaluate their skillset. The ability to read and produce drawings is fundamental to engineering practice. In order to use computer-aided design software effectively, students need to understand the concepts. This can be easily evaluated when hand-drawn plans are submitted.

\subsection{Prototyping the Design}

Despite some successful innovations, there was one major deficiency with the Design Trilogy prior to 2009 with reference to the original overall objective stated for the Design Trilogy - there had never been an opportunity for students to participate in the fabrication of a prototype 
of their design. This deficiency was addressed following the 2008-09 academic year with the decision to move the final two courses of the Design Trilogy into the final year of the program (one in the fall semester and one in the winter semester). Effectively, this created a year-long capstone course in the final year of the program. Although there is nothing innovative or unique about a year-long capstone course, the increased contact time with the students provided an opportunity for the students to be able to both design and prototype.

The first year-long offering of the final two Design Trilogy courses occurred during the 2009-10 academic year. In this configuration, students are required to have a design finalized by the end of the fall semester so that materials can be ordered and fabrication can begin early in the winter semester.

This new format has been followed for the past three academic years. While it is a challenge to identify industry problems that lend themselves to prototyping, the overall experience has been positive. A frequent comment made by students at the end of the year-long experience is that they were surprised by how much their design changed from what they believed to be the final design at the end of the fall semester to the design that was ultimately fabricated by the end of the winter semester. What is interesting to observe and discuss with students is the realization that they have to build what they design. It is much easier to stand up and talk about how something will work without having to demonstrate it. What may seem like a simple process, for example keeping a frame square, takes on new meaning when they have to do it. Students in this course are given weekly hands-on activities that incorporate welding, wood working, electrical, and machine shop practice to provide them with much of the requisite skills. One of our fundamental course objectives is that students internalize the need to provide clear, well thought out designs that appreciate the needs of the individuals and processes required to take their designs from paper to reality. There is much learning that takes place as the students attempt to fabricate what they have designed.

\section{FINAL THOUGHTS}

Industry expects engineers to have certain skills and knowledge by the time they enter the workforce. Industry relies on universities to play a key role in the "production" of these engineers. The Canadian Engineering Accreditation Board defines the 12 attributes that our engineering graduates (i.e., the "production" of our engineering programs) must possess. Several of these attributes can be addressed effectively in capstone courses. In many respects, the capstone course is the academic entity that best resembles the workplace experience in industry. Consequently, it is imperative that we devote sufficient attention to the development of the capstone experience.

The engineering design process is an extremely complex process. In fact, it is so complex that researchers have yet to fully describe how an experienced engineering designer is able to produce a solution to a problem. This poses challenges to the task of teaching inexperienced engineering students how to become successful engineering designers. A tool that we should not neglect as engineering educators is the tool of repetition. This tool is used frequently in the teaching of engineering knowledge when students are encouraged to complete multiple homework problems in preparation for similar problems on examinations. Similarly, the tool of repetition should be used in the teaching of engineering design (or perhaps in the "learning" of engineering design). The Design Trilogy was developed with the intent of providing multiple opportunities for engineering students to experience the process of finding an engineering solution to a problem. The mastery learning that is expected to accompany the use of repetition was structured so that greater expectations were required of students in each subsequent exposure to the design process. Ideally, it would be useful to provide engineering students with exposure to the design process in each year of their education.

In addition to providing opportunities for repetition (leading to mastery learning), however, it is necessary to create a capstone experience that reflects as many steps in the design process as possible. Traditionally, the capstone experience ends (from the student's perspective) with a design report describing the proposed solution. A problem with this approach is that students are not able to learn whether their proposed solution will be effective. Although the instructor may provide useful feedback, the learning activity has not been gleaned for maximum benefit. The opportunity for students to physically participate in the fabrication of a prototype of the proposed solution allows much more knowledge and experience to be gained by engineering students.

Finally, engineering instructors should not assume that engineering students are not good communicators because they (speaking in general terms) do not like technical communications courses. Our experience has been that most engineering students do appreciate the importance of communication skills when they can be incorporated into a more client-oriented learning environment, which to some extent mirrors what they will soon experience in industry. 


\section{Acknowledgements}

The authors would like to acknowledge the support for teaching innovation provided by Dr. Ron Britton, former NSERC Design Chairholder and Associate Dean (Design) in the Faculty of Engineering, University of Manitoba. Similarly, the authors would like to acknowledge a previous instructor of the first Design Trilogy course, Mr. Don Petkau. Finally, the authors would like to acknowledge the Biosystems Engineering Department Council members and our technicians for their willingness to support these ideas.

\section{References}

[1] L. Archer, Systematic method for designers. In Developments in Design Methodology, N. Cross (ed.) Chichester, UK: John Wiley \& Sons, 1984, 300 pp.

[2] Nigel Cross, Engineering Design Methods. Chichester, UK: John Wiley \& Sons, 1989, 151 pp.

[3] D. Dunn-Rankin, J.E. Bobrow, K.D. Mease and M.M. McCarthy, "Engineering design in industry: Teaching students and faculty to apply engineering science in design," Journal of Engineering Education, vol. 87 no. 3, pp. 219-222, 1988.

[4] E.W. Ernst and J.R. Lohmann, "Designing undergraduate design curricula," Journal of Engineering Education, vol. 80, no. 5 , pp. 543-547, 1990.

[5] M.J. French, Conceptual Design for Engineers. London, UK: Design Council, 1985.

[6] J.C. Jones, A method of systematic design. In Developments in Design Methodology, ed. N. Cross, Chichester, UK: John Wiley \& Sons, 1984.

[7] D.D. Mann, D.S. Petkau, K.J. Dick and S. Ingram, "Experiences with inter-year capstone design teams," in Proc. $C D E N / C^{2} E^{2}$ Conference. (Winnipeg, MB, 22-24 July 2007), 3 pp., 2007.

[8] D.D. Mann, S. Ingram, K.J. Dick, D.S. Petkau and M.G. Britton, "Re-thinking the placement of technical communication in the engineering curriculum," International Journal of Engineering Education, vol. 23, no. 4, pp. 645-649, 2007.

[9] G. Paul and W. Beitz. Engineering Design. London, UK: Design Council, 1984.

[10]S.M. Reiss, "Manufacturing: Education charts a new course," Optics and Photonics News, September 1992.

[11]H. Viets, "Designing across the curriculum," Journal of Engineering Education, vol. 80, no. 5, pp. 565-567, 1990. 